

\section{Sumário}

Dossiê TEMÁTICO: NOVOS INSTITUTOS JURÍDICOS DE LICITAÇÕES E CONTRATOS 17

I. LicitaÇõEs E CONTRATOS PÚBLICOS: PARTE GERAL. 18

INTEGRATED CONTRACT IN LAW 14.133/2021: NEW LAW, SAME PROBLEMS? A STUDY OF COMPARATIVE LAW .20

Paulo Afonso Cavichioli Carmona, Bruno Ribeiro Marques e Odilon Cavallari

Reajustamento de preços na Nova Lei de Licitações e Contratos Administrativos BRASILEIRA: O "Princípio" Da ANUALIDAde.

Ricardo Silveira Ribeiro e Bráulio Gomes Mendes Diniz

A nova Lei de Licitações, as encomendas tecnológicas e o diálogo competitivo .61 André Dias Fernandes e Débora de Oliveira Coutinho

LiCITAÇÕES, CONTRATOS E O IMPULSO À APRENDIZAGEM PROFISSIONAL: UM ESTUDO SOBRE A CONTRATAÇÃo de APRENDizes no ESTAdo do AMAZONAS, BRAsIL

Emerson Victor Hugo Costa de Sá, Natasha Yasmine Castelo Branco Donadon e Mauro Augusto Ponce de Leão Braga

Licitações, contratos e Modelo Brasileiro de Processo: notas sobre a viabilidade DA UTILIZAÇÃo DE FERRAMENTAS PROCESSUAIS PARA CONFERIR MAIOR EFICIÊNCIA ÀS AQUISIÇÕES PÚBLICAS

Claudio Madureira e Carlos André Luís Araujo

RESOlUÇão DE CONFLITOS COM A ADMINISTRAÇÃo PÚBLICA E A NOVA LEI DE LICITAÇÕES E CONTRATOS: REFORÇO DOS MEIOS ALTERNATIVOS.

Clarissa Sampaio Silva e Danille Maia Cruz

A Adesão do Brasil ao Acordo sobre Contratações Públicas da OMC: entre tabus e DIFICULDADES REAIS

Eduardo Ferreira Jordã e Luiz Filippe Esteves Cunha

II. Accountability e controle

A LEI N. ${ }^{\circ}$ 14.133/2021 E OS NOVOS LIMITES do CONTROLE EXTERNO: A NECESSÁRIA DEFERÊNCIA dos Tribunais de Contas em prol da Administração Pública .................................. 162 Ricardo Schneider Rodrigues

O CONTROLE DAS CONTRATAÇÕES PÚBliCAS E A NOVA LEI DE LICITAÇÕES: O QUE HÁ DE Novo? 183

Leandro Sarai, Flávio Garcia Cabral e Cristiane Rodrigues Iwakura 
Programa de compliance como exigênCia em licitações: ANálises EM Prol da QUALIFICAÇÃo DO PROCESSO LICITATÓRIO NO CONTEXTO DA LEI 14.133/2021.

Cristian Ricardo Wittmann e Anayara Fantinel Pedroso

A NOVA REALIDAde bRASILEIRA DE NECESSIDADE DE PROGRAMAS DE INTEGRIDADE DAS PESSOAS JURÍDICAS LICITANTES EM PROCESSOS LICITATÓRIOS DA ADMINISTRAÇÃO PÚBLICA 227

Fernando Silva Moreira dos Santos e Luiz Fernando de Oriani e Paulillo

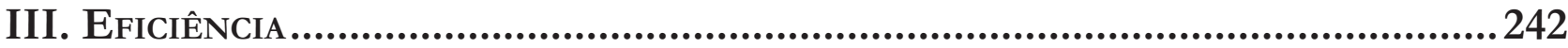

Efficiency contracts in the New Brazilian Procurement Law: conceptual FRAMEWORK AND INTERNATIONAL EXPERIENCE

Floriano de Azevedo Marques Neto, Hendrick Pinheiro e Tamara Cukiert

A gestão de riscos como instrumento para a aplicação efetiva do Princípio Constitucional dA EFICIÊNCIA.

Rafael Rabelo Nunes, Marcela Teixeira Batista Sidrim Perini e Inácio Emiliano Melo Mourão Pinto

IV. Contratação PÚblica No Direito ESTrangeiro

LA ADQUisición de VACUNAS CONTRA LA COVID-19 POR COLOMBIA: ENTRE LA CONFIDENCIALIDAD Y LA FALTA DE TRANSPARENCIA. 284

Gressy Kareny Rojas Cardona e David Mendieta

LA DISCRIMINACIÓN EX POST DE LOS OFERENTES DE UNA LICITACIÓN PÚBLICA COMO INFRACCIÓN ADMINISTRATIVA Y DE LIBRE COMPETÊNCIA 312 Jaime Arancibia Mattar

LA DISCRIMINACIÓN EX POST DE LOS OFERENTES DE UNA LICITACIÓN PÚBLICA COMO INFRACCIÓN ADMINISTRATIVA Y DE LIBRE COMPETÊNCIA..........................................................332 Udochukwu Uneke Alo, Obiamaka Adaeze Nwobu e Alex Adegboye

Outros Temas 348

I. Políticas públicas e institucionalidade

¿Existe El derecho humano a la identidad Cultural de los Migrantes en El Derecho INTERNACIONAL? 351 Juan Jorge Faundes e Glorimar Alejandra Leon Silva

El acceso a la justicia y el debido proceso ante el Tribunal Constitucional y la CorTe Suprema: dos NOCIONES DEL CONTENCIOSO ADMINISTRATIVO CHILENO .384 Pedro Harris Moya 
“Ministrocracia” E DECISÕES INDIVIDUAis CONTRAditórias No Supremo Tribunal FEDERAI

Ulisses Levy Silvério dos Reis e Emilio Peluso Neder Meyer

A POlÍtica de INOVAÇÃo COMO INSTRUMENTO DE REDUÇÃo DAS DESIGUALDADES REGIONAIS NO BRASIL

Caroline Viriato Memória e Uinie Caminha

Conflitos de Competência E A JudicializaÇão da Saúde no Federalismo Brasileiro.447 Jorge Leal Hanai, Luis Antônio Abrantes e Luiz Ismael Pereira

O Ministério Público no enfrentamento dos Reflexos da CRise da Covid-19: UMA

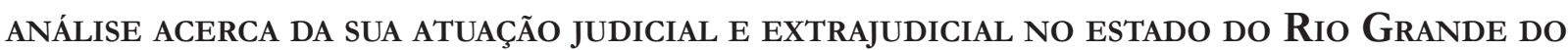
NorTE

Raquel Maria da Costa Silveira, Ana Mônica Medeiros Ferreira, Flávio Luiz Carneiro Cavalcanti e Haroldo Helinski Holanda

A CONSAgRaÇão CONSTITUCIONAL DA POlítica FALIMENTAR

Nuno de Oliveira Fernandes

II. Políticas públicas, grupos vulneráveis e litígios estruturais

LAS LIMITACIONES A LOS DERECHOS DE LOS GRUPOS VULNERABLES Y LOS SUJETOS DE ESPECIAL PROTECCIÓN DURANTE LA PANDEMIA Mary Luz Tobón Tobón

LitígIOS ESTRUTURAIS E A PROTEÇÃO DOS DIREITOS DOS POVOS INDÍGENAS DURANTE A PANDEMIA DE Covid-19: CONTRIBUições do ICCAL

Ana Carolina Lopes Olsen e Bianca M. Schneider van der Broocke

EPISTEMICÍDIO DAS NARRATIVAS NEGRAS E LITÍGIO ESTRUTURAL: INSTRUMENTOS EXTRAJUDICIAIS PARA DISSOLUÇÃO DO PROBLEMA NO SISTEMA EDUCACIONAL .......................................582

Vitor Fonsêca e Caroline da Silva Soares

Trajetórias E DiRETRIZES dAS POlíticas PÚbliCAS NACIONAIS PARA A POPULAÇão INFANTOJUVENIL EM SITUAÇÃO DE RUA...

Wânia Cláudia Gomes Di Lorenzo Lima, Cynthia Xavier de Carvalho e Maria Creusa de A. Borges

Emprendimiento como Fuente de Ingresos para las Víctimas del Conflicto Armado en el Marco de la Ley 1448 de Colombia. Reflexiones de la Implementación en el Valle del Cauca

Saulo Bravo García e Luz Marina Restrepo García

III. Políticas públicas e aÇão Restaurativa. 
JUSTIÇA RESTAURATIVA COMO AÇÃO COMUNICATIVA: EQUILÍBRIO ENTRE SISTEMA E MUNDO DA

Daniela Carvalho Almeida da Costa e Luciana Leonardo Ribeiro Silva de Araújo

JUSTIÇA RESTAURATIVA: ACORDOS E COOPERAÇÃO.................................................668

Samyle Regina Matos Oliveira e Selma Pereira de Santana 


\title{
A gestão de riscos como instrumento para a aplicação efetiva do Princípio Constitucional da Eficiência*
}

\author{
Risk management as an instrument to \\ balance the constitutional principles of \\ legality and efficiency
}

\author{
Rafael Rabelo Nunes** \\ Marcela Teixeira Batista Sidrim Perini**** \\ Inácio Emiliano Melo Mourão Pinto****
}

\section{Resumo}

Enfrentar o medo de responsabilização dos gestores públicos exige repensar a atuação do Estado e de suas instituições. A cultura de controle - por meios normativos e de fiscalização - evidenciou que ela não só não impediu a ocorrência de eventos de corrupção, mas teve um efeito adverso: a diminuição da eficiência do Estado. Esse ensaio teórico tem como objetivo discutir como a gestão de riscos pode se tornar um instrumento que contribui para o alcance dos objetivos de órgãos públicos, aplicando, de maneira efetiva, o Princípio da Eficiência. De forma sintética, isto é realizado ao se avaliarem, de forma ampla, várias classes de risco que podem impactar a consecução dos objetivos, e não majoritariamente riscos de corrupção. Para isso, é essencial discutir a importância da eficiência como princípio constitucional em contraponto às visões mais estreitas do Princípio da Legalidade. Isso posto, é possível utilizar a Teoria da Gestão de Riscos aceita internacionalmente para construir, de forma sistemática, decisões fundamentadas que possam ser validadas por várias instâncias - as chamadas linhas de defesa, e, assim, utilizar a gestão de riscos como instrumento de aplicação do Princípio da Eficiência, da mesma forma que a própria lei é o instrumento de aplicação do Princípio da Legalidade. Espera-se que, com isso, este ensaio possa contribuir com o debate do Princípio da Eficiência, principalmente quando os órgãos públicos conseguem criar uma estrutura para se gerenciar riscos com apoio da alta administração dos órgãos, da sua auditoria interna, e dos órgãos de controle externo.

Palavras-chave: Cultura de controles. Administração Pública. Valor público. Eficiência. Apagão das canetas.

Recebido em 25/07/2021

Aprovado em 10/02/2022

\footnotetext{
** Doutor em Engenharia Elétrica

E-mail: rafaelrabelo@unb.br
}

*** Especialista em Direito Público. MBA em Compliance e Governança Corporativa E-mail: advmarcelabatista@gmail.com

**** Especialista em Direito Público

E-mail: inacioemmp@gmail.com

\section{Abstract}

Facing the fear of being responsible for Brazilian public managers requires rethinking the actions of the State and its institutions. The culture of control — through normative and inspection means — evidenced that it 
not only did not prevent the occurrence of corruption events but also had an adverse effect: the decrease in the efficiency of the State. This theoretical essay aims to discuss how risk management can become an instrument that contributes to the achievement of the objectives of public agencies by effectively applying the principle of efficiency. Briefly, this is accomplished by broadly assessing various classes of risk that can impact objectives' achievement, not only corruption risks. For this, it is essential to discuss the importance of efficiency as a constitutional principle in counterpoint to the narrower views of the principle of legality. That said, it is possible to use the internationally accepted theory of risk management to systematically build justified decisions that various instances can validate - the so-called lines of defense, and thus use risk management as an instrument for the application of the principle of efficiency in the same way that the rules itself are an instrument for the application of the principle of legality. It is hoped that this essay can contribute to the debate on the principle of efficiency, especially when public agencies create a structure to manage risks with the support of the agencies' board of directors, their internal auditors, and the external control agencies.

Keywords: Control culture. Public administration. Public value. Efficiency. Fear of compromise.

\section{Introdução}

O risco sempre esteve presente em qualquer atividade humana. Os grandes avanços da humanidade tais como a exploração espacial, bem como a criação de vacinas - somente foram possíveis, pois alguém desafiou o estado das coisas, assumindo riscos ${ }^{1}$.

O conceito de risco é amplo e pode ser aplicado a qualquer projeto, tarefa ou empreitada; seja dentro de uma organização, seja na vida pessoal. Há risco quando houver dois fatores: um objetivo ou resultado a ser atingido e incerteza em seu atingimento. Desse modo, a partir do momento em que se define um objetivo, e há algum grau de incerteza, há o risco.

Muitas vezes, esse conceito é entendido, apenas, como o efeito negativo da incerteza no objetivo² ${ }^{2}$ Contudo, o conceito moderno de risco é entendido tanto em relação ao seu efeito negativo — a ameaça quanto positivo - a oportunidade ${ }^{3}$.

Já os controles são medidas que mantêm ou modificam os riscos. Eles incluem, mas não estão limitados a processos, políticas, dispositivos, práticas, ou quaisquer outras condições, sem, contudo, haver garantia de que eles exercerão, necessariamente, o efeito modificador pretendido no risco ${ }^{3}$.

Desse modo, gerir uma organização implica a busca por resultados e, inevitavelmente, pela necessidade de se enfrentar cada risco identificado, seja a respeito dos processos organizacionais já existentes, projetos, programas ou implementação de iniciativas, calibrando os controles de forma a materializar a sua estratégia. Independentemente da esfera de atuação — pública ou privada —, é desejável que os riscos sejam mantidos em níveis aceitáveis.

Os riscos têm diversas fontes e naturezas. Eles podem ser, por exemplo, riscos de imagem ou reputação; riscos legais; e riscos financeiros/orçamentários; e riscos operacionais ${ }^{4}$ (o que inclui o risco de qualidade dos produtos ou serviços; riscos de recursos humanos; riscos referentes à operação; riscos de segurança cibernética; entre outros). A materialização de um risco de qualquer natureza pode ter a potencialidade de

\footnotetext{
DAMODARAN, A. Gestão estratégica do risco: uma referência para a tomada de riscos empresariais. Porto Alegre-RS: Bookman, 2009.

2 BRASIL. Tribunal de Contas da União. Roteiro de Auditoria de Gestão de Riscos. Brasília. 2017.

3 ABNT. ABNT NBR ISO 31.000 - Gestão de Riscos - Diretrizes. Rio de Janeiro. 2018.

4 BRASIL. Ministério do Planejamento e Controladoria-Geral da União. Instrução Normativa Conjunta MP/CGU N. ${ }^{\circ}$ 01, 2016. Disponível em: <https://repositorio.cgu.gov.br/bitstream/1/33947/5/Instrucao\%20Normativa\%20Conjunta \%20MP-CGU\%20012016.pdf>. Acesso em: 08 jul 2021.
} 
comprometer os resultados esperados. Por esse motivo, qualquer avaliação de riscos que analise apenas uma classe de risco pode se tornar incompleta e, inclusive, dificultar a consecução de objetivos. Uma das diretrizes para uma boa gestão de riscos refere-se ao fato de que ela deve ser estruturada e abrangente ${ }^{5}$.

Nesse bojo, é compreensível que entidades privadas admitam certo nível de risco em busca de melhores resultados para entregar cada vez mais valor para seus clientes e acionistas. Por outro lado, entidades públicas não ambicionam retorno financeiro, mas entregar "respostas efetivas a necessidades ou demandas coletivas [...] politicamente desejadas [...] cujos resultados modifiquem aspectos da sociedade", o que é entendido como valor público.

Mas o que diferencia as organizações públicas das privadas? Será que uma é mais eficiente do que a outra? De certo modo, há o mito da ineficiência pública e da virtude das organizações privadas. As técnicas de gestão da segunda não necessariamente são aplicadas à primeira, já que há particularidades e complexidades inerentes à gestão estatal ${ }^{7}$. Contudo, há de se registrar que a segunda tem aparentemente maior flexibilidade na adoção de medidas para enfrentar riscos do que a primeira, visto que ao gestor público é imposto o Princípio da Legalidade, que, na sua visão clássica, dispõe que a ele somente seria dado fazer aquilo que a lei autorize de forma prévia e expressa, o que não se aplica aos organismos privados, já que a ele é possível fazer o que a lei não proíba. Trataremos, no momento apropriado, acerca da visão contemporânea desse princípio e veremos que a legalidade deve ser vista em um espectro mais amplo que esse vetusto brocardo.

A respeito da Administração Pública, uma classe de risco em que se procura mitigar com maior frequência são os riscos de corrupção. Nesse sentido, os procedimentos administrativos burocráticos são "impostos como mecanismos para [controlar essa classe de risco], principalmente quando envolve operação com agentes públicos" ${ }^{\prime}$. Mas o excesso dessa burocracia não tem sido suficiente para mitigar todos os riscos de corrupção. Além disso, tem implicado o efeito colateral tornar o estado ineficiente.

Se, de um lado, países como o Japão reconstroem, em apenas 6 dias, uma estrada após um terremoto'; o governo da capital do Brasil consegue recuperar um viaduto que desabou por falta de manutenção apenas após 15 meses $^{10}$. Fatos como esse tornam visíveis os sinais de ineficiência administrativa. "É necessário repensar nosso sistema de controle e revisitar os entendimentos que vêm dando conotações extensivamente rígidas e ortodoxas" ${ }^{\prime 1}$.

Ao se aprofundar em casos como esse, à luz da ótica de gestão de riscos, é possível verificar que a gestão pública brasileira e seu arcabouço jurídico têm prescrito controles que buscam mitigar, preferencialmente, uma classe de risco: o de corrupção. Seria como se riscos dessa natureza tivessem a maior probabilidade e magnitude de impactar, negativamente, os resultados da administração pública do que outras classes de risco. Contudo, os riscos de outras classes podem afetar resultados da mesma forma. Assim, instrumentaram-

\footnotetext{
5 ABNT. ABNT NBR ISO 31.000 - Gestão de Riscos - Diretrižes. Rio de Janeiro. 2018.

6 TEIXEIRA, V. A. Criando valor público - gestão estratégica no TCU. Página de Liderança, 2012. Disponível em: <http://portal2. tcu.gov.br/portal/page/portal/TCU/educacao_ corporativa/lideranca>. Acesso em: 02 jul 2021.

7 DE OLIVEIRA, R. A.; AZEREDO, A. D. O pináculo da virtude: o mito da ineficiência pública e a virtude do setor privado. Revista Sítio Novo, 5, n. 2, 2020. 36-44. Disponível em: <https://sitionovo.ifto.edu.br/index.php/sitionovo/article/view/894>. Acesso em: 9 jul. 2021.

8 LIMA, L. V. D. A.; RUFINO, M. A.; MACHADO, M. R. Criando dificuldades para vender facilidades: corrupção, burocracia e crescimento corporativo no Mercosul. Revista de Contabilidade e Organizações, 13, 2019. 64-74. Disponível em: < https://www.revistas. usp.br/rco/article/view/158324/157722>. Acesso em: 09 jul. 2021.

9 G1. Japão reconstrói rodovia destruída por terremoto em apenas seis dias. G1, 2011. Disponível em: <http://g1.globo.com/ tsunami-no-pacifico/noticia/2011/03/japao-reconstroi-rodovia-destruida-por-terremoto-em-apenas-seis-dias.html>. Acesso em: 2 jul. 2021.

${ }_{10}$ G1. Viaduto do Eixão que desabou há 15 meses será liberado nessa terça, diz GDF. G1, 2019. Disponível em: <https:// g1.globo.com/df/distrito-federal/noticia/2019/06/03/viaduto-de-eixao-que-desabou-ha-15-meses-sera-liberado-nesta-terca-dizgdf.ghtml>. Acesso em: 2 jul. 2021.

11 GUIMARÃES, F. V. O Direito Administrativo do Medo: a crise da ineficiência pelo controle. 2016. Disponível em <http://www.direitodoestado.com.br/colunistas/fernandovernalha-guimaraes/o-direito-administrativo-do-medo-a-crise-da-ineficiencia-pelo-controle>. Acesso em: 23 jan. 2022.
} 
-se, ainda mais, controles de corrupção, o que aumentou a probabilidade de ocorrência de outras classes de risco, fazendo com que o excesso de controles impactasse os resultados. Registra-se, também, a carência de incentivos para que os próprios agentes públicos possam simplificar os procedimentos, o que impacta o ambiente de negócios, sendo uma das causas para o baixo nível de investimento do Brasil ${ }^{12}$.

Ao mesmo tempo, estudos indicam que "processos mais dinâmicos poderiam levar à redução da corrupção, [já que é] possível que a corrupção se alimente da burocracia." ${ }^{13}$, e que ações em que se observem a transparência, a inovação e a confiança poderiam contribuir, de forma decisiva, com a redução da burocracia e da cultura da desconfiança ${ }^{14}$.

E como se libertar desse círculo vicioso? Como construir confiança em um ambiente de desconfiança? Como permitir que o administrador público se sinta à vontade em decidir com foco no resultado, e que siga ritos mais dinâmicos abandonando os demasiadamente burocráticos que já não se mostram suficientes para mitigar riscos de corrupção?

Esse trabalho apresenta um ensaio teórico com o objetivo discutir como a gestão de riscos pode se tornar um instrumento que pode permitir o alcance da visão sistêmica e integrada, com foco no resultado das organizações públicas para entregar valor público, e assim, contribuir para aplicar de maneira efetiva o princípio constitucional da eficiência.

Para isso, o texto segue a seguinte lógica: analisa-se, primeiramente, a cultura de legalidade e de controle no Brasil em que se demonstra como foi a sua evolução histórica em relação ao arcabouço jurídico brasileiro; aprofunda-se na consequência dessa cultura relativa à atuação do gestor público em seus atos diários; e, em seguida, analisa-se a eficiência e a sua relevância como princípio constitucional em contraponto às visões mais estreitas do Princípio da Legalidade. Logo em seguida, o texto aprofunda-se na Teoria da Gestão de Riscos, extrapolando os aspectos jurídicos e se nutrindo, também, de padrões internacionais do tema, em que se demonstra que, ao se avaliarem riscos de mais de uma classe, se abre a possibilidade de visão sistêmica e integrada e para decisões fundamentadas, desde que haja estrutura e processo definido para que os gestores públicos possam utilizar desse instrumento.

\section{Princípio da Legalidade e a cultura de controle no Brasil}

O marco histórico considerado como o surgimento do Direito Administrativo foi o advento da Revolução Francesa, com a instituição da limitação e a separação dos poderes do Estado e sua submissão a um ordenamento jurídico administrativo especializado distinto do direito civil ${ }^{15}$. É estreita a ligação entre o surgimento do Direito Administrativo, o Princípio da Legalidade e o próprio conceito de Estado de Direito ${ }^{16}$.

No Brasil, com a consolidação do Estado Democrático de Direito promovido pela Constituição de 1988, houve o ingresso do povo na trajetória política como protagonista do processo, momento em que as normas constitucionais conquistaram status pleno, qual seja uma lente por meio da qual se leem e se interpretam todas as normas infraconstitucionais ${ }^{17}$.

12 CAVALCANTE, L. R. Ambiente de negócios, insegurança jurídica e investimentos: elementos para a formulação de políticas públicas no Brasil. Direito e Desenvolvimento, v. 12, n. 1, p. 82-96, 29 jul. 2021.

${ }_{13}$ LIMA, L. V. D. A.; RUFINO, M. A.; MACHADO, M. R. Criando dificuldades para vender facilidades: corrupção, burocracia e crescimento corporativo no Mercosul. Revista de Contabilidade e Organizações, 13, 2019. 64-74. Disponível em: <https://www.revistas. usp.br/rco/article/view/158324/157722>. Acesso em: 09 jul. 2021.

${ }^{14}$ DE CARVALHO, L. B. Governo digital e direito administrativo: entre a burocracia, a confiança e a inovação. Revista de Direito Administrativo, São Paulo-SP, 279, 2020. 115-148.

15 MELLO, C. A. B. D. Curso de Direito Administrativo. São Paulo: Malheiros, 2013.

16 MENDES, G. F.; BRANCO, P. G. Curso de Direito Constitucional. $8^{a}$ Ed. São Paulo: Saraiva, 2013. p. 812-813.

17 FERRAZ, S. O controle da administração pública na Constituição de 1988. Revista de Direito Administrativo, 1992. p. 64-73. 
As suas emendas e legislação infraconstitucional, posteriormente editadas, estabeleceram uma série de princípios e deveres a serem observados pela Administração Pública, com a criação de rede de fiscalização de seus atos, sujeitando suas entidades e ocasionalmente os agentes públicos controles sobre sua atuação ${ }^{18}$.

A Constituição de 88 como afirmação da cidadania, e com o compromisso de promover o acesso ao direito fundamental à boa administração, fortaleceu instituições e normas que, diretamente ou indiretamente, controlam a atuação do Estado, com regras e princípios ${ }^{19}$, estes entendidos como as normas mais relevantes do ordenamento — os seus alicerces básicos — que permitem que a constituição se comunique melhor com a realidade fática subjacente, uma vez que permite interpretações, considerando-se as especificidades de cada $\operatorname{caso}^{20}$.

A questão recai não sobre a quantidade de normas e leis que regulam ações do administrador público, mas se elas conseguem alcançar o Direito Público do Estado contemporâneo, que visa satisfazer determinadas necessidades sociais, sendo vinculado ao atendimento eficiente dos fins sociais e fáticos aos quais se destina ${ }^{21}$.

No Quadro 1, apresenta-se uma lista exemplificativa não exaustiva de alguns normativos infraconstitucionais existentes, os quais delimitam a atuação do agente público e, nos termos de cada diploma legal, estabelecem punições nos casos de descumprimento. Diante disso, observa-se, no Brasil, a existência de diversas legislações que buscam implementar controles adequados à Administração Pública, assim como o combate aos desvios de conduta.

Quadro 1. Legislação aplicável aos agentes públicos

\begin{tabular}{|c|c|}
\hline Lei & Descrição \\
\hline Decreto-Lei n. ${ }^{\circ} 2.848 / 1940$ & Código Penal, especialmente nos crimes contra a administração pública \\
\hline Decreto-Lei n. ${ }^{\circ} 4.657 / 1942$ & $\begin{array}{l}\text { Lei de Introdução às normas do direito brasileiro, especialmente nos } \\
\text { artigos incluídos pela Lei n. }{ }^{\circ} 13.655 / 2018\end{array}$ \\
\hline Lei n. ${ }^{\circ} 8.429 / 1992$ & Lei de Improbidade Administrativa \\
\hline $\begin{array}{l}\text { Lei n. }{ }^{\circ} 8.666 / 1993 \\
\text { Lei n. }{ }^{\circ} 14.133 / 2021\end{array}$ & Lei de Licitações e Contratos Administrativos \\
\hline Lei n. ${ }^{\circ} 4.717 / 1965$ & Lei da Ação Popular \\
\hline Lei n. ${ }^{\circ} 7.347 / 1985$ & Lei de Ação Civil Pública \\
\hline Lei n. $12.527 / 2011$ & $\begin{array}{l}\text { Lei de Acesso à Informação, regulamentando o dever de transparência } \\
\text { do Poder Público }\end{array}$ \\
\hline Lei n. ${ }^{\circ} 12.529 / 2011$ & $\begin{array}{l}\text { Estrutura o Sistema Brasileiro de Defesa da Concorrência; dispõe sobre } \\
\text { a prevenção e repressão às infrações contra a ordem econômica; altera } \\
\text { a Lei n. } 8.137 \text {, de } 27 \text { de dezembro de } 1990 \text {, o Decreto-Lei n. }{ }^{\circ} 3.689 \text {, } \\
\text { de } 3 \text { de outubro de } 1941 \text { - Código de Processo Penal, e a Lei n. }{ }^{\circ} 7.347 \text {, } \\
\text { de } 24 \text { de julho de } 1985 \text {; revoga dispositivos da Lei no } 8.884 \text {, de } 11 \text { de } \\
\text { junho de } 1994 \text {, e a Lei n. }{ }^{\circ} 9.781 \text {, de } 19 \text { de janeiro de } 1999 \text {; e dá outras } \\
\text { providências. }\end{array}$ \\
\hline
\end{tabular}

\footnotetext{
${ }_{18}$ MODESTO, P. O controle jurídico do comportamento ético da Administração Pública no Brasil. Revista Eletrônica sobre a Reforma do Estado, 2007.

19 FREITAS, J. As políticas públicas e o direito fundamental à boa administração. Revista do Programa de Pós-Graduação em Direito - UFC, 2015. p.195-217.

${ }^{20}$ SOUZA NETO, C. P. de; SARMENTO, D. Direito constitucional: teoria, história e métodos de trabalho. Belo Horizonte-MG: Fórum, 2012.

${ }^{21}$ COMPARATO, F. K. Ensaio sobre o juizo de constitucionalidade de políticas públicas. São Paulo: Malheriros, v. 2, 1997.
} 


\begin{tabular}{|l|l|}
\hline Lei & Descrição \\
\hline Lei n. $^{\circ} 12.846 / 2013$ & $\begin{array}{l}\text { Lei Anticorrupção, traz a perspectiva da responsabilização objetiva das } \\
\text { pessoas jurídicas e ressalta um cuidado quanto à prática de ilícitos envol- } \\
\text { vendo a Administração Pública. }\end{array}$ \\
\hline Lei n. $^{\circ} 13.303 / 2016$ & $\begin{array}{l}\text { Lei sobre o Estatuto Jurídico da empresa pública, sociedade de econo- } \\
\text { mia mista e subsidiárias, União, Estados, Distrito Federal e Municípios, } \\
\text { impõe diversas novas responsabilidades e regras de governança às em- } \\
\text { presas estatais. }\end{array}$ \\
\hline Lei n. $^{\circ} 8.112 / 1990$ & $\begin{array}{l}\text { Dispõe sobre o regime jurídico dos servidores públicos civis da União, } \\
\text { das autarquias e das fundações públicas federais. }\end{array}$ \\
\hline
\end{tabular}

Fonte: os Autores.

Embora seja digna e positiva para a sociedade, a preocupação com o controle da ação estatal não foi suficiente para impedir a prática de arbitrariedades na Administração Pública ${ }^{22}$. Conforme dados de 2019 do Índice de Percepção da Corrupção (IPC) — principal indicador de corrupção no setor público do mundo —, o Brasil se manteve no pior patamar da série histórica ${ }^{23}$.

Essas questões intensificam questionamentos da sociedade sobre a capacidade de o governo atuar com lisura e ao mesmo tempo, com eficiência, e a percepção generalizada de que a corrupção é um dos principais problemas do país. Dessa forma, o controle da gestão pública torna-se uma pauta relevante no Brasil.

Os casos recorrentes de corrupção revelam que não somente o amplo espectro de controle por vias normativas não obstou a corrupção, como o próprio aparelho burocrático estatal serviu de instrumento para a sua prática. Esse intrincado de controles dos agentes públicos e o aumento da burocracia estatal configuram umas das principais causas da ineficiência não somente do próprio sistema de fiscalização da Administração Pública, mas como de sua atuação ordinária ${ }^{24}$.

Além disso, pode ocorrer a geração de conflitos entre os próprios controladores, acirrando a competição por maior espaço de atuação - recursos e vantagens, consequentemente e destoando da própria economicidade exigida da atuação estatal, já que o sistema anticorrupção brasileiro pode ser classificado como multiagência, pois não conta com um órgão autônomo anticorrupção a exemplo de Singapura, mas de vários órgãos com competências fiscalizatórias (preventivas, repressivas, e de responsabilização) ${ }^{25}$. É conveniente existirem instâncias controladoras independentes diversas. Ocorre, porém, que a propagação desses instrumentos não foi acompanhada de uma coordenação da atuação das estruturas criadas ${ }^{26}$. Há órgãos de fiscalização, que, em contrariedade à lógica racional, investigam, de forma isolada, os mesmos fatos ao mesmo tempo, muitas vezes para apurarem as mesmas responsabilidades. O problema não é a pluralidade de órgãos, mas a falta de coordenação entre eles ${ }^{27}$.

\footnotetext{
${ }^{22}$ POWER, T.; TAYLOR, M. M. Corruption and Democracy in Brazil: The Struggle for Accountability. [S.l.]: University of Notre Dame Press, 2011.

23 TRANSPARÊNCIA INTERNACIONAL. Índice de Percepção da Corrupção 2019. Transparência Internacional, 2019. Disponível em: <https://transparenciainternacional.org.br/ipc/>.

${ }^{24}$ CAMPANA, P. D. S. P. A cultura do medo na administração pública e a ineficiência gerada pelo atual sistema de controle. Revista de Direito, 2017. 189-216.

25 OLIVEIRA, G. J. D. A insegurança jurídica das empresas e os acordos de leniência na legislação anticorrupção brasileira. Migalhas, 2017. Disponível em: <https://www.migalhas.com.br/depeso/259553/a-inseguranca-juridica-das-empresas-e-os-acordos-deleniencia-na-legislacao-anticorrupcao-brasileira>. Acesso em: 20 de março de 2020.

26 CAMPANA, P. D. S. P. A cultura do medo na administração pública e a ineficiência gerada pelo atual sistema de controle. Revista de Direito, 2017. 189-216.

27 LOUREIRO, M. R. G. Série Pensando o Direito - N. ${ }^{\circ} 33 / 2019$, Coordenação do Sistema de Controle da Administração Pública Federal. Brasília, 2009. Disponível em: <http://pensando.mj.gov.br/wp-content/uploads/2015/07/33Pensando_Direito1.pdf>.
} 
O sistema normativo anticorrupção brasileiro "é composto por um conjunto de leis dispersas, estruturando em esferas autônomas de responsabilização e executado por uma série de órgãos independentes e, muitas vezes, sem canais institucionais de comunicação entre si” e, por consequente, "há elevada insegurança jurídica, incoerência entre as disposições normativas e, com isso, o combate à corrupção e a efetividade dos princípios da integridade e moralidade administrativa restam prejudicados" ${ }^{28}$. Não há como afirmar que o conjunto normativo minimamente listado, seja parte de um único sistema capaz de prevenir, detectar e punir a corrupção.

Quando leis como essas são promulgadas, é comum que o Estado as faça visando fomentar a confiança no sistema jurídico e político. O legislador, pressionado pelo público, elabora leis para satisfazê-los, sem que se tenham condições de efetivação das respectivas normas, há a formulação da chamada "legislação-álibi", por meio da qual busca se liberar das pressões políticas ou apresentar o Estado como sensível às exigências e expectativas dos cidadãos, apaziguando os cenários de crise, mas obstruindo caminhos de construção de medidas efetivas ${ }^{29}$.

Aliado a tudo isso, pouco se discute sobre modelo organizacional dos órgãos e formas adequadas de controle da ação pública. Conforme os diversos relatos de corrupção, a abordagem de que o aumento do número de mecanismos de controle é diretamente proporcional à efetividade nos desvios de conduta do agente público não se apresenta coerente ${ }^{30}$.

\section{0 ambiente de controle e a consequência na atuação do gestor público em seus atos diários - 0 "apagão das canetas"}

Considerando-se a grande quantidade de diplomas normativos, órgãos de controle e fiscalização existentes, outro ponto de discussão recai sobre o alcance da eficiência da Administração Pública, mesmo quando todos os requisitos de legalidade são devidamente cumpridos.

O gestor público, em sua atuação diária, em geral, analisa os casos concretos sob a avaliação binária e estática, se certa iniciativa é permitida pelo ordenamento jurídico, se é legal, ou ainda, qual a consequência de sua decisão. Isso o leva, naturalmente, a interpretar as normas administrativas sem dar tanta ênfase a outros princípios, colocando a legalidade acima de todos. Agir, assim, é considerar o direito contemporâneo como um sistema fechado de conceitos, próprio de uma sociedade estática, o que é inconciliável com a época atual $^{31}$.

Assim, o administrador público vai lentamente desistindo de decidir, não deseja correr riscos, ficando em sua zona de conforto, sem encontrar soluções aos interesses administrativos, apenas se protegendo. Em consequência dessa retração, o processo decisório fica afetado, instalando-se uma ineficiência administrativa, com reflexo no funcionamento da atividade pública ${ }^{32}$. Mas isso vai contra o que se espera do gestor público, já que obedecer tão somente à legislação não é suficiente para se entregar valor público. Espera-se do Estado a "redução do desemprego, o crescimento econômico, o combate à pobreza, solução para os problemas

\footnotetext{
${ }_{28}$ MACIEL, C. S. F. dos S.; AVELAR, M. M. Atos lesivos à Administração Pública e o princípio do bis in idem: uma análise do sistema legal de defesa da integridade administrativa. In: FORTINI, Cristiana (Coord). Corrupção e seus múltiplos enfoques jurídicos. Belo Horizonte: Fórum, 2018. p. 83-117

${ }^{29}$ NEVES, Marcelo. A constitucionalização simbólica. São Paulo: WMF Martins Fontes, 2018.

30 ALVES, M. F. C.; CALMON, P. C. D. P. Múltiplas Chibatas?Governança da Política de Controle da Gestão Pública Federal. ANPAD - Encontro de Administração Pública e Governança. Salvador-BA: [s.n.]. 2008. p. 1-16.

31 RIBEIRO, L. C. O direito administrativo como caixa de ferramentas e suas estratégias. Revista de Direito Administrativo, v. 272 , 2016. 209-249.

32 GUIMARÃES, F. V. O Direito Administrativo do Medo: a crise da ineficiência pelo controle, 2016. Disponível em: < http://www.direitodoestado.com.br/colunistas/fernando-vernalha-guimaraes/o-direito-administrativo-do-medo-a-crise-da-ineficiencia-pelo-controle $>$.
} 
de habitação e saúde"33. E uma atuação baseada, apenas, em regulamentação e na mitigação completa de riscos - lembremo-nos das suas facetas positiva e negativa - mina a inovação, a criatividade e a solução. "Quando os soviéticos tentaram banir da existência a incerteza por meio da regulamentação e do planejamento governamentais, sufocaram o progresso social e econômico" 34 . Merece destaque a análise sobre os possíveis atrasos sociais causados por agentes públicos que, ao se depararem com uma demanda fora do padrão cotidiano, optam por decidir pela ótica binária, qual seja: se está na lei [ou em seus normativos regulamentadores] ou não. Afinal, na dúvida, dorme tranquilo quem indefere ${ }^{35}$, frustrando o mais fundamental objetivo do Estado. A isso já se tem um nome: o "apagão das canetas". "A hipertrofia do controle gera a infantilização da gestão pública"36.

De forma a minimizar isso, tem-se o art. 28 do Decreto-Lei n. ${ }^{\circ}$ 4.657/42 — incluído pela Lei 13.655/2018, a Lei de Introdução às Normas do Direito Brasileiro (LINDB) — que busca diminuir a insegurança do agente público na tomada de decisão cuja motivação tivera sido positiva, honesta. Essa seria uma espécie de cláusula geral do erro administrativo, que reconhece o agente público como ser humano comum, ou seja, falível, sujeito a $\operatorname{erros}^{37}$. Se, por uma via, a responsabilização do agente se mostra viável nos casos de dolo e erro grosseiro, pode ocasionar a repressão e o desestímulo nos casos de corrupção ou fraude. De outra mão, ao admitir o erro, salvo quando grosseiro, viabiliza-se um regime jurídico que abre oportunidades para soluções inovadoras, aumentando as possibilidades para a Administração Pública. Quanto à responsabilização do agente público, o art. 28 da LINDB, que trata sobre a responsabilidade pessoal do agente público por suas decisões ou opiniões técnicas ou erro grosseiro, destaca que a responsabilização do agente público depende de um juízo de culpabilidade. Se assim não o fosse, estaria se negando à falibilidade humana "errare bumanum est", e inibiria a tentativa de novas práticas administrativas. A maior virtude do dispositivo é "criar um ambiente propício à inventividade, cuidando de gestores e técnicos que buscam inovar os meios de gestão pública e se suas tentativas de inovação não forem bem-sucedidas, eles apenas responderão por dolo ou erro grosseiro" 38 .

Entretanto, a insegurança jurídica é uma realidade para o gestor público, já que não há possibilidade de previsão de todos os eventos possíveis e muito tempo de regulamentar todos eles, já que, legislar demora, e os cenários mudam. Nesse contexto, como garantir um ambiente favorável à inovação e eficiência para o administrador público bem-intencionado e que quer inovar, mas sabe que suas ideias e procedimentos podem estar eventualmente errados ${ }^{32}$ ?

A reflexão, neste artigo, assenta-se no desejo por uma Administração Pública eficiente e com visão sistêmica, submetida a uma avaliação contínua de seus impactos, observando-se seus efeitos diretos e colaterais de regulação, formulação e ainda implementação de políticas públicas ${ }^{39}$, ao mesmo tempo, proteger o gestor com boas motivações, e que ele tenha condições de assumir riscos no exercício da administração, de deferir

\footnotetext{
33 GROISMAN, E. Crisis y Actualidad del Derecho Administrativo Económico. Revista de Derecho Industrial, 1993. 894.

34 BERNSTEIN, P. Desafio aos Deuses: A Fascinante História do Risco. Rio de Janeiro: Elsevier, 2011.

35 CAMPANA, P. D. S. P. A cultura do medo na administração pública e a ineficiência gerada pelo atual sistema de controle. Revista de Direito, 2017. 189-216.

36 DANTAS, B. O risco de infantilizar a gestão pública por Bruno Dantas, 2018. Disponível em: <https://jornalggn.com.br/ gestao-publica/o-risco-de-infantilizar-a-gestao-publica-por-bruno-dantas/>. Acesso em 23 jan. 2022.

37 PALMA, J. B. D. Quem é o 'administrador médio' do TCU?, 2018. Disponível em: <https://www.jota.info/paywall?redirect_to=// www.jota.info/opiniao-e-analise/colunas/controle-publico/quem-e-o-administrador-medio-do-tcu-22082018>. Acesso em: 01 de maio de 2020.

38 BINENBOJM, G.; CYRINO, A. O Art. 28 da LINDB - A cláusula geral do erro administrativo. Revista de Direito Administrativo, 2018. 203-224. Disponível em: <http://bibliotecadigital.fgv.br/ojs/index.php/rda/article/view/77655>.

39 FREITAS, J. As políticas públicas e o direito fundamental à boa administração. Revista do Programa de Pós-Graduação em Direito UFC, 2015. 195-217.
} 
e de dormir bem ${ }^{40}$. Do contrário, ele será incentivado, apenas, a cumprir os ritos da administração sem se preocupar com os resultados ${ }^{41}$.

\section{A eficiência e a sua relevância como princípio constitucional em contraponto às visões mais estreitas do Princípio da Legalidade}

O desafio pós-moderno do Estado é ser eficiente, sem renunciar às conquistas democráticas-constitucionais ${ }^{42}$. Essa eficiência não se trata da maximização do lucro, mas sim como um melhor exercício das missões de interesse coletivo que incumbe ao Estado, que deve obter a maior realização prática possível das finalidades do ordenamento jurídico, com o menor ônus possível, tanto para o próprio Estado, especialmente de índole financeira, como para as liberdades dos cidadãos ${ }^{43}$.

Algumas leis infraconstitucionais já traziam, desde muito tempo, a necessidade de o estado ser eficiente, a exemplo do Decreto-lei 200/6744. Contudo, apenas após a Reforma Administrativa proposta pela Emenda Constitucional n. ${ }^{\circ}$ 19/1998, o Princípio da Eficiência passou a integrar o caput do artigo 37 da Constituição Federal juntamente aos Princípios da Legalidade, impessoalidade, moralidade e publicidade. Antes dessa emenda, a eficiência era tratada, apenas, como um princípio constitucional implícito ${ }^{45}$.

Dessa forma, todos os cinco princípios devem se comunicar mutuamente, não se excluindo no grupo de interpretação do ordenamento jurídico, possuindo uma função não apenas programática, mas fornecendo diretrizes situadas no cume do sistema a serem seguidas por todos os aplicadores de direito ${ }^{46}$, não podendo ser encarados como nichos isolados incomunicáveis ${ }^{47}$.

A Emenda Constitucional de n. ${ }^{\circ} 45$ de 2004, que reformou o Judiciário, trouxe avanços normativos ao princípio da eficiência. Apesar de entender que a eficiência é algo mais do que desejável, essas evoluções não conseguiram transpor a dificuldade em se perceber de forma mais objetiva tal princípio, já que ela é vista por demais fluida e de difícil controle pelo Direito. A eficiência chega a ser vista por alguns autores como um adorno, uma aspiração que não pode ser concebida senão na intimidade do princípio da legalidade, visto que sua busca jamais poderia ser justificativa para postergar o princípio da boa administração, muito mais amplo e dever do administrador. Não se pode esquecer de que a eficiência, enquanto finalidade, possui alcance bem maior, pois, em sua não aplicação concreta, reside a diferença entre uma ação estatal errática, confusa, inefetiva; ou de uma ação planejada, consciente, sóbria, respeitosa e focada na efetiva produção de resultados úteis à sociedade ${ }^{48}$.

Importante, também, destacar que a diferença conceitual entre a eficiência, eficácia e efetividade nunca passou despercebida pelos doutrinadores administrativistas: a primeira tem sentido relacionado ao modo como se processa a atividade administrativa, a segunda relaciona-se aos meios e instrumentos utilizados e a

\footnotetext{
40 PALMA, J. B. D. Quem é o 〈administrador médio〉 do TCU?, 2018. Disponível em: <https://www.jota.info/paywall?redirect_ to $=/ /$ www.jota.info/opiniao-e-analise/colunas/controle-publico/quem-e-o-administrador-medio-do-tcu-22082018>. Acesso em: 01 de maio de 2020.

41 BINENBOJM, G.; CYRINO, A. O Art. 28 da LINDB - A cláusula geral do erro administrativo. Revista de Direito Administrativo, 2018. 203-224. Disponível em: <http://bibliotecadigital.fgv.br/ojs/index.php/rda/article/view/77655>.

${ }^{42}$ RIBEIRO, L. C. O direito administrativo como caixa de ferramentas e suas estratégias. Revista de Direito Administrativo, 2016. 209-249.

${ }^{43}$ FRANCESCO, M. Principio di Legalità e Semplificazione Dell'attività amministrativa. Profili Critici e Principi Ricostruttivi. Nápoles: Maggio, 2000.

44 MORAES, A. D. Direito Constitucional. São Paulo: Atlas, 2004.

45 COELHO, J. Princípio de Eficiência: parâmetro para uma nova gestão. Revista do TCU, p. 122-123, 2011.

46 MEIRELLES, H. L. Direito Administrativo Brasileiro - 29ed. São Paulo: Malheiros, 2004.

47 FRANÇA, V. D. R. Eficiência administrativa na Constituição Federal. Revista de Direito Administrativo, 2000. 165-177.

48 MELLO, C. A. B. D. Curso de Direito Administrativo. São Paulo: Malheiros, 2013.
} 
terceira tem respaldo nos resultados obtidos ${ }^{49}$. Pode haver uma sem as outras, no entanto, não se descuida que o desejável é que as três caminhem simultaneamente. Alguns denominam o Princípio da Eficiência como a "qualidade do serviço prestado" 45 . Com o advento do Princípio da Eficiência, a Administração Pública passou "a legitimar-se também em razão do resultado obtido", evidenciando, assim, um desapego à diferença formal entre os institutos ${ }^{50}$. O que se busca ao fim é a realização dos interesses da coletividade, ou seja, o já mencionado "valor público".

Apesar disso, e justamente pela sua fluidez e difícil controle, o Princípio da Eficiência vem sendo utilizado, quase que unicamente, como recurso hermenêutico para a análise de situações fáticas, principalmente nos casos em que se faz necessário temperar a aplicação do princípio da legalidade em prol do atendimento pragmático de alguma necessidade real aplicando o princípio à posteriori dos atos administrativos. Pouco se recorre ao Princípio da Eficiência com a finalidade de utilizá-lo na perspectiva de uma diretriz de uma atuação intrinsecamente orientada para a finalidade que seu conteúdo expressa: a ação administrativa eficiente do Estado ${ }^{51}$. Dessa forma, aplicando o princípio à priori aos atos administrativos.

O Princípio da Eficiência não pode ser visto, apenas, como meio, nem adereço ao Princípio da Legalidade visto que a própria emenda constitucional n. ${ }^{0}$ 19/1998 pretendeu trazer à lume a boa administração, capaz de proporcionar bem-estar ao cidadão, permitindo, inclusive, que leis infraconstitucionais utilizem mecanismos inovadores, com o argumento de que estão em comunhão com o Princípio da Eficiência ${ }^{52}$.

Nesse ponto, o possível conflito entre os princípios da eficiência e da legalidade perpassam muito mais na visão e escopo desse segundo que da própria força normativa do primeiro.

A visão clássica do Princípio da Legalidade, em que os indivíduos no campo privado podem fazer tudo o que a lei não proíba, e a Administração Pública somente pode atuar em situações em que a lei a autorize, é de Hely Lopes Meirelles, que teve a primeira edição de seu "Direito Administrativo Brasileiro" em 1964". Uma interpretação estrita do vetusto brocardo pode levar a uma paralisia administrativa na falta de qualquer norma que autorize a ação do Estado dessa ou daquela forma.

A visão moderna da legalidade prima pelo respeito à segurança jurídica, pelo respeito e aplicação do art. $5^{\circ}$, inciso II, da Constituição Federal, em que "ninguém será obrigado a fazer ou deixar de fazer alguma coisa senão em virtude de lei". Ou seja, a legalidade, mais que mandatória com relação à Administração Pública, é instrumento de proteção das liberdades individuais, a lei é o instrumento que garante a liberdade, e não o inverso ${ }^{54}$.

Ainda, alguns chegam a conceituar o legislador contemporâneo como um "legislador motorizado", que é profícuo em normatizar. No entanto, perdendo as normas o caráter geral e abstrato, com um excesso de normas setoriais, concretas e temporárias. Isso levaria a uma "crise da legalidade" em que o remédio seria justamente observado no intento das constituições contemporâneas de formar uma unidade normativa por meio de princípios $^{50}$.

Desse modo, essa visão moderna da legalidade não faz referência a um tipo de norma específica, sob ponto de vista estrutural, mas ao próprio ordenamento em sentido material. Surge assim um bloco de legalidade ou bloco de constitucionalidade, visto que a Lei passa a referir-se à norma jurídica, seja ela uma regra ou um princípio, esteja prevista na constituição ou em lei em sentido estrito ${ }^{50}$.

Desta feita, considerando o Princípio da Legalidade com base nessa ótica moderna, temos que "o princípio da eficiência de forma alguma visa mitigar ou ponderar o princípio da legalidade, mas sim embebê-la

49 CARVAlho FILHO, J. dos S. Manual de Direito Administrativo. São Paulo: Atlas, 2017, p. 33.

${ }^{50}$ MENDES, G. F.; BRANCO, P. G. Curso de Direito Constitucional. $8^{a}$ Ed. São Paulo: Saraiva, 2013, p. 812-817.

51 COELHO, J. Princípio de Eficiência: parâmetro para uma nova gestão. Revista do TCU, p. 122-123, 2011.

52 MODESTO, P. O controle jurídico do comportamento ético da Administração Pública no Brasil. Revista Eletrônica sobre a Reforma

do Estado, 2007.

53 MEIRELLES, H. L. Direito Administrativo Brasileiro - 29ed. São Paulo: Malheiros, 2004.

${ }^{54}$ MENDES, G. F.; BRANCO, P. G. Curso de Direito Constitucional. $8^{a}$ Ed. São Paulo: Saraiva, 2013, p. 812-817. 
de uma nova lógica, determinando a insurgência de uma legalidade finalística e material [...] e não mais uma legalidade meramente formal e abstrata" ${ }^{5}$.

Ressalta-se que a eficiência surgiu para se unir aos demais princípios impostos à administração, não podendo sobrepor-se a nenhum deles, em especial ao da legalidade, sob risco de gerar sérios danos à segurança jurídica e ao próprio Estado de Direito.

No outro extremo, o excesso normativo e regulatório, que pode ser entendido como Princípio da Legalidade sob uma ótica estreita, muitas vezes, se traduz em excesso de controles realizados por vários órgãos de contas, em que há a fiscalização dos mesmos problemas por vários órgãos, padecendo de ineficiência o Estado, com várias pessoas fazendo a mesma tarefa ${ }^{56}$. E, adicionalmente, quando surgem eventos de corrupção e desvios de conduta, aumenta-se a inclinação para se incrementarem os instrumentos de controle existentes. No entanto, tornar o processo mais burocrático, além de aumentar os custos para o Estado, pode não resolver o problema ${ }^{57}$.

Em um primeiro olhar, se percebe, então, um conflito entre o Princípio da Eficiência e o da Legalidade, ou mesmo entre o primeiro e determinadas normas-regras que sejam contraproducentes a ponto de sua aplicação sem ponderação levar a uma total ineficiência estatal, ferindo, assim, irremediavelmente, o próprio interesse público primário.

Nesse ponto é importante mencionar, pelo menos, duas importantes correntes doutrinárias que tratam da forma de aplicação dos princípios e a sua diferenciação da aplicação das regras.

Segundo Dworkin, as regras representam comandos disjuntivos, em que a sua aplicação obedece ao padrão de "tudo ou nada", ou seja, ou aplica-se ou refuta-se. Para resolver os conflitos aparentes entre as regras, utilizam-se dos critérios formais de resolução de antinomias: cronológico, hierárquico e de especialidade. Já os princípios não devem ser sopesados por esses mesmos critérios, já que a decisão entre a aplicação entre um ou outro dependerá da análise do caso em questão. Após essa análise, impregnada pela argumentação moral, definir-se-á qual princípio será utilizado em detrimento do outro ${ }^{58}$. Apesar de alguns apontarem Dworkin como um adepto da ponderação de princípios, essa técnica não é por ele avalizada, pois, para ele, um princípio deve ser o escolhido para preponderar em um hard case $e^{59}$.

O jurista que defende a ponderação de princípios é o igualmente notório - e bastante lembrado na nossa Suprema Corte, especialmente pelo Min. Gilmar Mendes - Robert Alexy ${ }^{60}$. Para este os princípios podem ser considerados "mandados de otimização", a serem obedecidos dentro das possibilidades fáticas e jurídicas do caso concreto. Assim, é possível o cumprimento dos princípios em graus diferentes, não apenas no plano fático, mas também no jurídico. Incidindo em um caso concreto em rotas de colisão, pode cada um ceder na sua solução, sendo efetuada a ponderação de princípios. Para especificar o quanto cada princípio poderia ceder em um caso concreto, Alexy desenvolveu a Teoria da Proporcionalidade, e, apesar de alguns entenderem como um princípio, é entendida por outros como um postulado normativo, uma terceira espécie de normas, inconfundível com regras e princípios. Seria uma metanorma, ou norma de $2^{\circ}$ grau, apresentando os critérios para a aplicação de outras normas ${ }^{61}$.

\footnotetext{
55 ARAGÃO, A. S. D. O princípio da eficiência. Revista de Direito Administrativo, 2004. 1-6. Disponível em: < http://bibliotecadigital. fgv.br/ojs/index.php/rda/article/view/44361>.

56 OLIVEIRA, G. J. D. A insegurança jurídica das empresas e os acordos de leniência na legislação anticorrupção brasileira. Migalhas, 2017. Disponível em: <https://www.migalhas.com.br/depeso/259553/a-inseguranca-juridica-das-empresas-e-os-acordos-deleniencia-na-legislacao-anticorrupcao-brasileira>. Acesso em: 20 de março de 2020.

57 GUIMARÃES, F. V. O Direito Administrativo do Medo: a crise da ineficiência pelo controle, 2016. Disponível em: < http://www.direitodoestado.com.br/colunistas/fernando-vernalha-guimaraes/o-direito-administrativo-do-medo-a-crise-da-ineficiencia-pelo-controle>.

58 DWORKING, R. The model of rules. Univeristy of Chicago Law Review, 1967. p. 14-46.

59 DWORKIN, R. Do liberty and equality conflict? In: BARKER, P. Living as Equals, 1996. p. 39-58.

${ }^{60}$ ALEXY, R. Teoria dos Direitos Fundamentais. São Paulo: Malheiros. 2008. p. 85-179.

${ }^{61}$ SOUZA NETO, C. P. de; SARMENTO, D. Direito constitucional: teoria, história e métodos de trabalho. Belo Horizonte-MG: Fórum,
} 
A colisão entre normas constitucionais, seja entre princípios, entre regras ou entre estes e aqueles, é objeto de intenso debate doutrinário. Há acirrada discussão acerca de técnicas e teorias voltadas a tratar do assunto como: categorização, teoria interna dos direitos fundamentais, critérios clássicos de resolução de antinomias, ponderação, entre outros. O fato é que o surgimento da eficiência como um princípio expresso da Administração Pública merece uma tutela mais atenta e específica dos eventuais conflitos que surjam de modo a comprometer a sua aplicação na Administração Pública. Seja o conflito apontado contra o Princípio da Legalidade — em virtude de uma visão clássica e estreita deste — seja contra qualquer norma-regra que torne ineficiente a atuação estatal de modo a tirar-lhe sobremodo sua eficiência.

Uma saída seria o estabelecimento de marco regulatório entre instâncias superiores da administração, voltadas ao estabelecimento de estratégias mais gerais; e os órgãos inferiores direcionados à sua implementação, com flexibilização organizacional supervisionada, sob o olhar da eficiência ${ }^{62}$.

Mas como implementar esse marco regulatório? Normas — que geralmente são a forma de se materializar esses marcos regulatórios - podem demorar a ser implementadas, e, assim, ser ineficientes. Justamente porque, quando se analisam as possíveis causas de ineficiência na administração pública, tem sido privilegiada uma estrutura essencialmente burocrática de controle, desprezando os aspectos finalísticos da administração pública ${ }^{63}$. A adoção, no Brasil, de um sistema jurídico demasiadamente normatizado implicou o fomento da burocracia, e, com isso, a ineficiência. O excesso de normas no país gerou um ciclo vicioso, em que o medo de responsabilização dos agentes públicos em decorrência de violação às normas pode afastar o bom senso e a criação de soluções eficazes para os problemas, dando espaço a indeferimento de ações sob a pálida justificativa da falta de regulamentações ${ }^{64}$.

A administração pública gerencial engloba o valor da eficiência, quando identifica a necessidade de definir objetivos e operacionalizar resultados, bem como a flexibilização frente aos recursos e processos, admitindo, assim, a simetria mais lógica aos fins desejados da administração ${ }^{65}$. "A crise administrativa manifesta-se na baixa capacidade de formulação, informação, planejamento, implementação e controle das políticas públicas. O rol de insuficiências da administração pública no país é dramático" ${ }^{06}$.

Nesse contexto, evidencia-se a necessidade de o gestor público adotar ferramentas que contribuam para o alcance de visão sistêmica e integrada da administração pública, contribuindo para a melhoria de processos e fomento da inovação nos bens e serviços disponibilizados à sociedade, sem deixar de obedecer à legalidade, que é sua obrigação.

Como temperar a aplicação dos princípios da legalidade e da eficiência no momento da prática do ato, sem que haja necessidade de se utilizarem recursos hermenêuticos de análises a posterior? E, ainda, como criar esse marco regulatório de forma a se obter a flexibilização organizacional supervisionada?

2012. p. 392-393.

62 BENTO, L. V. Governança e governabilidade na reforma do estado: entre eficiência e democratização. Barueri: Manole, 2003.

63 GUIMARÃES, F. V. O Direito Administrativo do Medo: a crise da ineficiência pelo controle, 2016. Disponível em: < http://www.direitodoestado.com.br/colunistas/fernando-vernalha-guimaraes/o-direito-administrativo-do-medo-a-crise-da-ineficiencia-pelo-controle $>$.

64 LUNELLI, R. G. M. O princípio da eficiência no art. 37 da Constituição Federal: a burocratização da desburocratização, 2014. Disponível em: <https://jus.com.br/artigos/28675/o-principio-da-eficiencia-no-art-37-da-constituicao-federal-a-burocratizacao-da-desburocratizacao>. Acesso em: 02 de fevereiro de 2020.

${ }^{65}$ OLIVEIRA, K. P. D.; PAULA, A. P. P. D. Hebert Simon e os limites do critério de eficiência na administração pública. Cadernos de Gestão Pública e Cidadania, 2014. 113-126.

66 PEREIRA, A. C. M. Trinta anos de controle da Administração Pública: À espera de um giro de eficiência. In: HACHEM, D. W.; LEAL, F.; MENDONÇA, J. V. S. D. Transformações do Direito Administrativo: O Estado Administrativo 30 anos depois da Constituição de 1988. Rio de Janeiro: FGV, 2018. p. 27-61. 


\section{A gestão de riscos, a legalidade e a eficiência}

Nessa altura, fica claro que a Administração Pública vem se excedendo no uso de controles em geral, para mitigar riscos preferencialmente de uma classe, o de corrupção, e deixa de avaliar riscos de outra natureza.

Ao mesmo tempo, como os controles implementados na administração pública brasileira, para enfrentar essa classe de risco, são, em sua maioria, normativos — que estão diretamente ligados ao princípio da legalidade - , questiona-se: seria facultado ao gestor público avaliar riscos de outra natureza? Seria possível se falar em flexibilizar controles normativos em favor da eficiência?

Antes de enfrentar esses questionamentos, o Tribunal de Contas da União (TCU) tem envidado esforços para reforçar a necessidade de as políticas públicas atenderem às demandas sociais e entregar o melhor valor à população realizando uma gestão de riscos eficaz ${ }^{67}$.

Nesse sentido, o que realmente o principal órgão de controle externo brasileiro espera? Seria mesmo avaliar, de forma mais ampla, as classes dos riscos que podem atingir os resultados das ações dos órgãos da administração pública? Isso inclui colocar, no mesmo bojo, a análise de riscos de corrupção, riscos operacionais, riscos de imagem, entre outros, já que, claramente, considerar, preferencialmente, uma classe de riscos e controles não é gerenciar riscos de maneira eficaz?

Destaca-se que excerto do Guia de Auditoria em Gestão de Riscos ${ }^{68}$, publicado pelo TCU, está em linha com o propósito da gestão de riscos definidos pela Organização Internacional para Padronização (ISO), e pela Associação Brasileira de Normas Técnicas (ABNT) que é a criação e proteção de valor ao melhorar o desempenho, encorajar a inovação e apoiar o alcance de objetivos ${ }^{69}$. Essa visão, para a gestão de riscos, vem, cada vez mais, sendo aceita. As normas ISO que tratam da Gestão de Qualidade (ISO 9.000); e da Gestão Ambiental (ISO 14.000) passaram a tornar mandatório o desenvolvimento de uma mentalidade de riscos para que os produtos e serviços sejam providos com qualidade ${ }^{70}$ e com consciência ambiental ${ }^{71}$. Ou seja: produto e serviço só é entregue com qualidade caso se tenha como suporte, uma boa gestão de riscos; produtos e serviços só são entregues com responsabilidade socioambiental caso se tenha como suporte uma boa gestão de riscos. Não se pode deixar de mencionar, também, a própria Tecnologia da Informação. A entrega de novos sistemas e de novos serviços sem avaliação de riscos de segurança da informação pode ser catastrófica ${ }^{72}$.

Segundo a norma internacional de gestão de riscos ISO 31.000, traduzida no Brasil pela ABNT, "gerenciar riscos baseia-se em [considerar] princípios, estrutura e processo" "73. Ou seja, para se gerenciar riscos, deve-se observar essas três dimensões, que serão avaliadas nas seções a seguir, adaptando-a para a visão da gestão pública.

\footnotetext{
${ }^{67}$ BRASIL. Roteiro de Auditoria de Gestão de Riscos. Tribunal de Contas da União. Brasília. 2017.

68 O Tribunal de Contas da União (TCU), no documento intitulado Roteiro de Auditoria de Gestão de Riscos que é utilizado como referência para os seus auditores nessa matéria, destaca que "Gerenciar riscos de modo eficaz contribui para o aumento da confiança dos cidadãos nas organizações públicas ao subsidiar informações para a tomada de decisão, contribuir para um melhor desempenho na realização dos objetivos de políticas, organizações e serviços públicos e auxiliar na prevenção de perdas e no gerenciamento de incidentes”. BRASIL. Roteiro de Auditoria de Gestão de Riscos. Tribunal de Contas da União. Brasília. 2017.

69 ABNT. ABNT NBR ISO 31.000 - Gestão de Riscos - Diretrizes. Rio de Janeiro. 2018.

70 ASSOCIAÇÃO BRASILEIRA DE NORMAS TÉCNICAS. ABNT NBR ISO 9.001 - Sistemas de gestão da qualidade - guia para implementação. Rio de Janeiro: ABNT, 2015.

71 ASSOCIAÇÃO BRASILEIRA DE NORMAS TÉCNICAS. ABNT NBR ISO 14.001 - Sistemas de gestão ambiental - Requisitos com orientações para uso. Rio de Janeiro: ABNT, 2015.

${ }^{72}$ MOREIRA, F. R.; DA SILVA FILHO, D. A.; NZE, G. D. A.; DE SOUSA JÚNIOR, R. T.; NUNES, R. R. Evaluating the Performance of NIST's Framework Cibersecurity Controls Throught a Constructivist Multicriteria Methodology. IEEE Access. v. 9. p. 129605-129618, 2021.

73 ABNT. ABNT NBR ISO 31.000 - Gestão de Riscos - Diretrizes. Rio de Janeiro. 2018.
} 


\subsection{Os princípios da gestão de riscos e a administração pública}

A última versão da norma internacional ISO 31.000 diz que a Gestão de Riscos é regida por oito princí$\operatorname{pios}^{74}$, que estão listados no Quadro 2.

Quadro 2 - princípios da gestão de Riscos com suas devidas descrições

\begin{tabular}{|l|l|}
\hline Princípio & Descrição \\
\hline Integrada & A gestão de riscos é parte integrante de todas as atividades organizacionais. \\
\hline $\begin{array}{l}\text { Estruturada e } \\
\text { abrangente }\end{array}$ & $\begin{array}{l}\text { Uma abordagem estruturada e abrangente para a gestão de riscos contribui para resul- } \\
\text { tados consistentes e comparáveis. }\end{array}$ \\
\hline Personalizada & $\begin{array}{l}\text { A estrutura e o processo de gestão de riscos são personalizados e proporcionais aos } \\
\text { contextos externo e interno da organização relacionados aos seus objetivos. }\end{array}$ \\
\hline Inclusiva & $\begin{array}{l}\text { O envolvimento apropriado e oportuno de partes interessadas possibilita que seus co- } \\
\text { nhecimentos, pontos de vista e percepções sejam considerados. Isto resulta em melhor } \\
\text { conscientização e gestão de riscos fundamentada. }\end{array}$ \\
\hline Dinâmica & $\begin{array}{l}\text { Riscos podem emergir, mudar ou desaparecer à medida que os contextos externo e } \\
\text { interno de uma organização mudem. A gestão de riscos antecipa, detecta, reconhece e } \\
\text { responde a estas mudanças e eventos de uma maneira apropriada e oportuna. }\end{array}$ \\
\hline $\begin{array}{l}\text { Melhor infor- } \\
\text { mação pos- } \\
\text { sível }\end{array}$ & $\begin{array}{l}\text { As entradas para a gestão de riscos são baseadas em informações históricas e atuais, } \\
\text { bem como suas expectativas futuras. A gestão de riscos explicitamente leva em consi- } \\
\text { deração quaisquer limitações e incertezas associadas a estas informações e expectativas. } \\
\text { Convém que a informação seja oportuna, clara e disponível para as partes interessadas } \\
\text { pertinentes. }\end{array}$ \\
\hline $\begin{array}{l}\text { Fatores huma- } \\
\text { nos e culturais }\end{array}$ & $\begin{array}{l}\text { O comportamento humano e a cultura influenciam significativamente todos os aspec- } \\
\text { tos de riscos em cada nível e estágio. }\end{array}$ \\
\hline $\begin{array}{l}\text { Melhoria con- } \\
\text { tínua }\end{array}$ & $\begin{array}{l}\text { A gestão de riscos é melhorada continuamente por meio do aprendizado e experiên- } \\
\text { cias. }\end{array}$ \\
\hline
\end{tabular}

Fonte: ABNT (2018).

Se for analisado como o Estado brasileiro vem enfrentando os riscos com foco em controles pré-definidos em vez de ter foco no resultado de se gerar valor público, torna-se possível compreender como os princípios da gestão de riscos não estão sendo naturalmente atendidos.

Ao se aceitar controles-padrão para todas as situações, sem análise e avaliação de cada contexto - o que é comum no contexto organizacional da Administração Pública - não se observa o Princípio "Dinâmica" da Gestão de Riscos. Como leis e regulamentos demoram para serem produzidos e publicados, é possível que não seja possível antecipar, detectar, reconhecer e responder à mudanças e eventos de maneira apropriada e oportuna.

Ao se atribuir peso demasiado a uma classe de risco em detrimento de outra, se viola o Princípio "Estruturada e Abrangente" da Gestão de Riscos, já que apenas uma visão integral de cada situação permite avaliar todas as possibilidades, e assim, obter resultados consistentes e comparáveis.

Outro princípio não atendido é o da gestão de riscos "integrada". Se assim o fosse, cada unidade, cada processo de trabalho, cada projeto, e cada contratação da Administração Pública teria os riscos mapeados e claramente gerenciados.

\footnotetext{
${ }_{74}$ Importante ressaltar que a norma ISO 31.000, também, se utiliza de princípios na sua concepção. A filosofia é a mesma dos princípios constitucionais que já foi tratado anteriormente nesse texto.
} 
Importante ressaltar que não é objetivo deste trabalho se aprofundar ainda mais sobre a análise da observância de cada um desses princípios da gestão de riscos pela administração pública, e inclusive, sugere-se que esse ponto seja objeto de trabalhos futuros, em que se possam analisar casos de sucesso, e insucesso da Administração Pública sob esse prisma.

Importante ressaltar que a literatura demonstra que a internalização desses princípios pelas organizações e por seus colaboradores em todos os níveis pode traduzir em um enfrentamento eficaz dos riscos ${ }^{75}$, e, se o TCU espera uma gestão de riscos eficaz, é importante que se fomente a observância de cada um dos Princípios da Gestão de Riscos dentro da gestão pública.

\subsection{A estrutura da gestão de riscos e a Administração Pública}

Outro ponto relevante dentro da gestão de riscos é a existência de uma estrutura que permita que essa disciplina seja conduzida dentro das organizações. A norma ISO 31.000 ressalta que o propósito da existência de uma estrutura de gestão é a de apoiar a organização na integração dessa disciplina em funções e atividades significativas.

Para isso, a norma internacional destaca a necessidade de que haja liderança e comprometimento da alta administração dos órgãos e organismos com a gestão de riscos, pois é ela que assegurará a integração da gestão de riscos em atividades e funções que eles julguem significativas.

Nessa linha, é possível verificar que diversos órgãos relevantes da administração pública vêm publicando guias e políticas para gerenciamento de seus riscos nos últimos anos, ratificadas pelos seus dirigentes máximos, tais como o Guia de Gestão de Riscos do Supremo Tribunal Federal (STF) ${ }^{76}$; Guia de Gestão de Riscos do Superior Tribunal de Justiça (STJ) ${ }^{77}$; Metodologia de Gestão de Riscos da Controladoria Geral da União $(\mathrm{CGU})^{78}$, mas o quanto disso é para cumprir determinações do TCU, e o quanto é para se gerenciar efetivamente os riscos?

Para ajudar na resposta dessa reflexão, um outro ponto a se observar refere-se ao fato de haver, dentro das estruturas dos órgãos, unidades e/ou papéis que dividam a responsabilidade pelos riscos. O modelo da gestão de riscos pelas três linhas de defesa, definido pelo Instituto Internacional de Auditores Internos (IIA), ajuda a compreender um pouco como as organizações deveriam se estruturar. Nesse modelo, os riscos não seriam gerenciados por uma área ou um papel, mas sim compartilhado em três áreas ou papéis (as três linhas). A primeira e segunda linha seriam responsáveis pela gestão (podendo ser combinadas e/ou separadas), e a terceira linha, pela auditoria interna da organização ${ }^{7980}$

\footnotetext{
75 OLECHOWSKI, A. et al. The professionalization of risk management: What role can the ISO 31000 risk management principles play. International Journal of Project Management, v. 34, p. 1568-1578, 2016.

${ }_{76}$ BRASIL. Supremo Tribunal Federal. Guia de Gestão de Riscos, Brasília, 2019. Disponível em: <http://www.stf.jus.br/arquivo/ $\mathrm{cms} /$ centralDoCidadaoAcessoInformacaoGestaoEstrategica/anexo/GestaodeRiscos/GuiaGestaodeRiscos.pdf $>$. Acesso em: 13 jul. 2021.

${ }_{77}$ BRASIL. Superior Tribunal de Justiça. Guia de Gestão de Riscos, Brasília, 2016. Disponível em: <https://www.stj.jus.br/static_ files/STJ/Institucional/Gest\%C3\%A30\%20estrat\%C3\%A9gica/6_gestao_riscos_21jun.pdf>. Acesso em: 13 jul. 2021.

78 BRASIL. Controladoria-Geral da União. Metodologia de Gestão de Riscos, 2018. Disponível em: <https://repositorio.cgu.gov.br/ bitstream/1/41833/5/Metodologia_gestao_riscos_2018.pdf>. Acesso em: 13 jul. 2021.

79 THE INSTITUTE OF INTERNAL AUDITORS. Modelo das três linhas do IIA 2020: uma atualização das três linhas de defesa, Lake Mary, 2020. Disponível em: <https:/iiabrasil.org.br/korbilload/upl/editorHTML/uploadDireto/20200758glob-theditorHTML-00000013-20072020131817.pdf>. Acesso em: 02 jul 2021.

${ }^{80}$ Para o Modelo das Três Linhas do IIA, o que diferencia a primeira linha da segunda é que "[...] alguns papéis de segunda linha podem ser atribuídos a especialistas, para fornecer conhecimentos complementares, apoio, monitoramento e questionamento àqueles com papéis de primeira linha. Os papéis de segunda linha podem se concentrar em objetivos específicos do gerenciamento de riscos, como: conformidade com leis, regulamentos e comportamento ético aceitável; controle interno; segurança da informação e tecnologia; sustentabilidade; e avaliação da qualidade". THE INSTITUTE OF INTERNAL AUDITORS. Modelo das três linhas do IIA 2020: uma atualização das três linhas de defesa, Lake Mary, 2020. Disponível em: < https://iiabrasil.org.br/korbilload/upl/ editorHTML/uploadDireto/20200758glob-th-editorHTML-00000013-20072020131817.pdf>. Acesso em: 02 jul 2021.
} 
A importância desse modelo refere-se à possibilidade de reavaliação dos riscos sob óticas diferentes, em momentos diferentes, o que garante que as atividades e os objetivos estejam alinhados com os interesses na geração do valor público com a maximização de resultados.

Registra-se que é comum encontrar, nos órgãos públicos, seções ou divisões que têm um papel de segunda linha, contudo eles absorvem atribuição para avaliação rígida para riscos de conformidade (ou de legalidade), em que, muitas vezes, há a atribuição de verificar se o ato administrativo é ou não previsto em alguma norma ou regulamento interno da instituição, limitando-se a essa fronteira. Como exemplo, há as seções ou divisões que cuidam de legislação de licitações; ou seções ou divisões que cuidam de legislação de pessoal, por exemplo.

Se as atribuições de unidades como essas fossem ampliadas para se avaliarem riscos de forma abrangente com foco no resultado pretendido, e não apenas no sim/não da existência e conformidade das normas, abrir-se-ia a possibilidade se aplicar, de forma estruturada, a Teoria da Fundamentação da Decisão Administrativa, em que se aplica a hermenêutica ${ }^{81}$, agregando-se, ainda mais, informações qualitativas e quantitativas sobre as probabilidades e impactos de cada um dos eventos de risco identificados e como eles podem modificar os resultados pretendidos. Nesse cenário, as seções e/ou divisões de legislação de pessoal, e de licitação, passariam a ser chamadas, respectivamente, de seção/divisão de gestão de riscos de pessoal; e seção/divisão de riscos de licitação.

Não é objetivo deste trabalho aprofundar ainda mais nessa questão da estrutura da gestão de riscos em órgãos públicos já que se entende que esse ponto extrapola o escopo desse ensaio. Aproveita-se para deixar como sugestão de trabalho futuro a avaliação de como está a estruturação das linhas de defesa nos órgãos públicos, bem como os seus métodos e metodologias para gestão de riscos, e o escopo de quais classes de risco vêm sendo avaliadas por essas estruturas.

\subsection{O processo da gestão de riscos e a Administração Pública}

Por fim, tem-se o processo de gestão de riscos. É nele que, efetivamente, se identificam, se analisam e se avaliam os riscos. O processo de avaliação de riscos deve ser realizado de forma estruturada, utilizando metodologia definida e personalizada para cada órgão (como os publicados pelos guias e metodologias) e sua operacionalização realizada pela aplicação de técnicas específicas. A norma ISO 31.010, por exemplo, traz, em sua versão do ano de 2012, trinta e três técnicas diferentes ${ }^{82}$. Os guias e metodologias publicados e relatados na seção anterior pelos órgãos da Administração Pública selecionam algumas dessas técnicas — de acordo com a sua necessidade — para compor o seu processo de avaliação de riscos.

Em um contexto onde há uma estrutura para se gerenciar riscos, e se fomente a observância dos princípios da gestão de riscos, fica fácil imaginar que, toda vez em que se julgasse necessário, por exemplo, em hard cases, a primeira linha (a gestão) poderia realizar a avaliação de riscos de um determinado escopo, como uma demanda específica que já seria negada por algum normativo já existente, mas que porventura seja fatalmente contraprodutivo; ou, então, um processo de trabalho; um projeto; uma nova contratação. Qualquer que seja o objeto de avaliação de riscos, esse deveria ser feito com foco no resultado, e não nos controles (muitas vezes materializados por meio de normas).

A saída de uma atividade como essa seria um documento onde todas as alternativas e riscos seriam expostos, com detalhes do contexto externo e interno, e dos cenários, permitindo uma decisão fundamentada. A segunda linha poderia, então, avaliar as atividades realizadas, e dar o seu parecer, ratificando ou não o

\footnotetext{
81 DEZAN, S.; LOPES, A. Elementos para uma teoria da fundamentação da decisão administrativa: uma abordagem à luz da hermenêutica. Revista de Direito Administrativo \& Constitucional, v. 21, n. 83, 2021.

82 ASSOCIAÇÃO BRASILEIRA DE NORMAS TÉCNICAS. ABNT NBR ISO/IEC 31010 - Gestão de riscos - Técnicas para o processo de avaliação de riscos. Rio de Janeiro: ABNT, 2012.
} 
processo realizado. E a terceira linha poderia revisitar os atos praticados em momento oportuno, a posteriori, sempre com foco na melhoria contínua.

Dessa forma, cada caso concreto poderia ter uma construção de fundamentos que apoiasse o processo decisório, sendo realizada de maneira estruturada e com foco no resultado pretendido, em que se aplicariam controles na medida do necessário, e não de forma indiscriminada e rígida.

Há registro de um caso prático documentado em literatura que revela como um processo de avaliação de riscos foi aplicado, e como impactou, diretamente, na busca de eficiência, inovação, diminuição de custos e aumento da transparência dos próprios controles.

Trata-se do modelo para atendimento às demandas de deslocamentos dos agentes públicos do poder executivo federal, em que a solução encontrada foi a mudança de estratégia, saindo de um modelo de "posse" de veículos para investir no conceito de mobilidade, o que gerou o TaxiGov ${ }^{83}$.

Essa mudança somente foi possível após se avaliar os riscos e demais aspectos atinentes à análise de estratégia com foco no resultado [o deslocamento de servidores à serviço], e com isso, o táxi foi a alternativa que se mostrou mais eficiente para a Administração Pública Federal. Essa implementação permitiu uma redução de gastos de $60 \%$ em comparação ao modelo anteriormente utilizado, melhoria da qualidade dos serviços prestados (avaliação média pelos usuários foi de 4,97 em uma escala de 0 a 5), além da melhoria dos controles, em conformidade com os normativos vigentes (ou seja, obedecendo a legalidade). O foco na entrega do resultado permitiu a avaliação de riscos de diversas naturezas, com o seu devido enfrentamento ${ }^{82}$.

\subsection{Reflexões sobre a legalidade e a eficiência}

Mas seria possível reproduzir essa visão e modificar a estrutura organizacional dos órgãos públicos? Como focar nos resultados sem deixar de observar o Princípio da Legalidade?

O fomento dos princípios da gestão de riscos nas organizações públicas; a estruturação do assunto nos órgãos com a implantação da visão das três linhas em temáticas relevantes; e a aplicação do processo de gestão de riscos em cada caso concreto que saia do padrão, ou que enseje uma mudança ou inovação, sem dúvidas, permitiria extrair o máximo do gerenciamento de riscos: preservar e agregar valor às organizações ${ }^{84}$; impactar, positivamente, a qualidade dos serviços públicos ofertados ao cidadão ${ }^{85}$ e contribuir com o "aumento da confiança dos cidadãos nas organizações públicas"

Isso porque os controles — que são medidas que atuam no risco — nem sempre são efetivos quando são aplicados indiscriminadamente. Se se refletir, será que a falta de uma gestão de riscos abrangente não é um dos motivos pelo qual os brasileiros têm a percepção de que outros países são mais eficientes do que o nosso?

Dessa forma, está aí a importância de o gestor público se apropriar da gestão de riscos para uma avaliação dos graus de incerteza existentes no processo decisório. O gerenciamento adequado de riscos gera impactos para toda a sociedade ${ }^{87}$.

\footnotetext{
83 OLLAIK, L. G. Casoteca de Gestão Pública. TÁXIGOV: Inovando no Serviço de Mobilidade de Servidores, 2018. Disponível em: < https://repositorio.enap.gov.br/handle/1/3454>. Acesso em: 30 de março de 2020.

${ }^{84}$ MIRANDA, R. F. D. A. Implementando a gestão de riscos no setor público. Belo Horizonte: Fórum, 2019.

${ }^{85}$ MONTEZANO, L. et al. Percepção de Servidores Públicos Quanto à Implementação da Gestão de Riscos em uma Secretaria do Governo Federal do Brasil. Economia \& Gestão, 2019. 77-94.

86 BRASIL. Roteiro de Auditoria de Gestão de Riscos. Tribunal de Contas da União. Brasília. 2017.

87 MONTEZANO, L. et al. Percepção de Servidores Públicos Quanto à Implementação da Gestão de Riscos em uma Secretaria do Governo Federal do Brasil. Economia \& Gestão, 2019. 77-94.
} 
E qual é o objetivo da administração pública: não é entregar valor público na medida que o resultado dessas ações cause transformações e impactem, positivamente, a sociedade? ${ }^{88}$ Ou o objetivo da Administração Pública é seguir ritos e normas cegamente?

"É necessário que as organizações disponham de uma estrutura de gerenciamento de riscos e de governança corporativa" $"$.

\section{Considerações finais}

Esse trabalho realizou um ensaio teórico com o objetivo de demonstrar como a gestão de riscos pode ser uma ferramenta para a aplicação efetiva do Princípio Constitucional da Eficiência.

Para isso, primeiramente se discutiu sobre a cultura do controle e da legalidade, e de como essas ações não se mostraram suficientes para mitigar os riscos de corrupção, e ainda não foram suficientes para que a administração pública atingisse os resultados desejados. Foi exposto que a atuação do Estado, baseada somente na observância estrita dos normativos vigentes, pode contribuir para o fracasso no resultado das políticas públicas, potencializando o aumento da burocracia nos processos administrativos, e também, refletindo na atuação ordinária do agente público chegando a paralisias o qual é chamado de "apagão das canetas".

Em seguida, o artigo trouxe o histórico e reflexões sobre o Princípio Constitucional da Eficiência, trazendo um contraponto às visões mais estreitas do princípio da legalidade. Dessa forma, foi possível trazer reflexões de como uma avaliação de riscos com foco na avaliação abrangente de várias classes de risco (e não apenas de corrupção), observando-se os princípios da gestão de riscos, em relação à estruturação do tema dentro das organizações, e da aplicação de um processo sistemático de avaliação de riscos pode contribuir para a melhor reflexão sobre controles existentes na administração pública.

Espera-se que esse ensaio tenha conseguido demonstrar, mesmo que teoricamente, como a gestão de riscos pode atuar como ferramenta fomentar a aplicação do princípio da eficiência. E coloca-se uma reflexão: será que a gestão de riscos pode se tornar um instrumento para aplicar o Princípio da Eficiência da mesma forma que a lei é para aplicar o Princípio da Legalidade?

Alguns trabalhos futuros já foram sugeridos ao longo do texto como avaliar a observância dos princípios da gestão de riscos dentro da administração pública; ou avaliar a existência das três linhas dentro dos órgãos públicos. Mas também fica como sugestão a monitoração de ações de gestão de riscos, desenvolvidas para administração pública brasileira, de forma a validar a viabilidade das propostas colocadas nesse ensaio; ou ainda, se possível, a implantação e acompanhamento de projetos-piloto nos órgãos públicos com o foco na avaliação de riscos gerais; e não apenas de riscos legais.

Por fim, somente será possível superar, efetivamente, o apagão das canetas com a compreensão da alta administração dos órgãos públicos, da auditoria interna, e principalmente, dos órgãos de controle externo de que, efetivamente, não há mais como continuar insistindo na cultura de aplicação de controles e mais controles, sem visão crítica com olhar no resultado pretendido. Afinal, por mais que o administrador médio possa ser bem-intencionado e queira produzir resultados ${ }^{90}$, uma só andorinha não faz verão.

\footnotetext{
${ }^{88}$ LOPES, K.; MACADAR, M. A.; LUCIANO, E. M. Valor Público: o Cidadão no Centro da Gestão Pública. In: BARBOSA, A. F. Pesquisa Sobre o Uso das Tecnologias de Informação e Comunicação no Setor Público Brasileiro. [S.l.]: [s.n.], 2018. p. 75-84.

89 INSTITUTO BRASILEIRO DE GOVERNANÇA CORPORATIVA. Gerenciamento de riscos corporativos: evolução em governança e estratégia. São Paulo-SP: IBGC, 2017.

90 PALMA, J. B. D. Quem é o ‘administrador médio’ do TCU?, 2018. Disponível em: <https://www.jota.info/paywall?redirect_ to $=/ /$ www.jota.info/opiniao-e-analise/colunas/controle-publico/quem-e-o-administrador-medio-do-tcu-22082018>. Acesso em: 01 de maio de 2020.
} 


\section{Agradecimentos}

O autor Rafael Rabelo Nunes agradece o suporte do Ministério da Justiça e Segurança Pública representado pela Diretoria de Tecnologia da Informação e Comunicação (TED DTIC/SE/MJSP 01/2019); do Centro Universitário Atenas, Paracatu-MG; e do Centro de Pesquisa em Gestão, Inovação e Sustentabilidade da Universidade de Brasília.

\section{Referências}

ALEXY, R. Teoria dos Direitos Fundamentais. São Paulo: Malheiros. 2008. p. 85-179.

ALVES, M. F. C.; CALMON, P. C. D. P. Múltiplas Chibatas? - Governança da Política de Controle da Gestão Pública Federal. ANPAD - Encontro de Administração Pública e Governança. Salvador-BA: [s.n.]. 2008. p. 1-16.

ARAGÃO, A. S. D. O princípio da eficiência. Revista de Direito Administrativo, 2004. 1-6. Disponível em: $<$ http://bibliotecadigital.fgv.br/ojs/index.php/rda/article/view/44361>.

ASSOCIAÇÃO BRASILEIRA DE NORMAS TÉCNICAS. Gestão de riscos - Técnicas para o processo de avaliação de riscos. Rio de Janeiro-RJ: ABNT, 2012.

ASSOCIAÇÃO BRASILEIRA DE NORMAS TÉCNICAS. ABNT NBR ISO 14.001 - Sistemas de gestão ambiental - Requisitos com orientações para uso. Rio de Janeiro: ABNT, 2015a.

ASSOCIAÇÃO BRASILEIRA DE NORMAS TÉCNICAS. ABNT NBR ISO 9.001 - Sistemas de gestão da qualidade - guia para implementação. Rio de Janeiro: ABNT, 2015b.

ASSOCIAÇÃO BRASILEIRA DE NORMAS TÉCNICAS. ABNT NBR ISO 31.000 - Gestão de Riscos - Diretrizes. Rio de Janeiro. 2018.

BENTO, L. V. Governança e governabilidade na reforma do estado: entre eficiência e democratização. Barueri: Manole, 2003.

BERNSTEIN, P. Desafio aos Deuses: A Fascinante História do Risco. Rio de Janeiro: Elsevier, 2011.

BINENBOJM, G.; CYRINO, A. O Art. 28 da LINDB - A cláusula geral do erro administrativo. Revista de Direito Administrativo, 2018. 203-224. Disponível em: < http://bibliotecadigital.fgv.br/ojs/index.php/rda/ article/view/77655>.

BRASIL. Ministério do Planejamento e Controladoria-Geral da União. Instrucão Normativa Conjunta MP/ CGU N. ${ }^{\circ}$ 01, 2016. Disponível em: <https:// repositorio.cgu.gov.br/bitstream/1/33947/5/Instrucao\%20 Normativa\%20Conjunta\%20MP-CGU\%2001-2016.pdf>. Acesso em: 08 jul 2021.

BRASIL. Superior Tribunal de Justiça. Guia de Gestão de Riscos, Brasília, 2016. Disponível em: <https://www. stj.jus.br/static_files/STJ/Institucional/Gest $\%$ C3\%A30\%20estrat $\%$ C3\%A9gica/6_gestao_riscos_21jun. pdf>. Acesso em: 13 jul. 2021.

BRASIL. Roteiro de Auditoria de Gestão de Riscos. Tribunal de Contas da União. Brasília. 2017.

BRASIL. Controladoria-Geral da União. Metodologia de Gestão de Riscos, 2018. Disponível em: <https:/ / repositorio.cgu.gov.br/bitstream/1/41833/5/Metodologia_gestao_riscos_2018.pdf>. Acesso em: 13 jul. 2021.

BRASIL. Supremo Tribunal Federal. Guia de Gestão de Riscos, Brasília, 2019. Disponível em: <http://www. stf.jus.br/arquivo/cms/centralDoCidadaoAcessoInformacaoGestaoEstrategica/anexo/GestaodeRiscos / GuiaGestaodeRiscos.pdf>. Acesso em: 13 jul. 2021.

BRASIL. Controladoria-Geral da União. Metodologia de Gestão de Riscos. Brasília: CGU, 2018. 
CAMPANA, P. D. S. P. A cultura do medo na administração pública e a ineficiência gerada pelo atual sistema de controle. Revista de Direito, 2017. 189-216.

CAVALCANTE, L. R. Ambiente de negócios, insegurança jurídica e investimentos: elementos para a formulação de políticas públicas no Brasil. Direito e Desenvolvimento, v. 12, n. 1, p. 82-96, 29 jul. 2021.

COELHO, J. Princípio de Eficiência: parâmetro para uma nova gestão. Revista do TCU, p. 122-123, 2011.

COMPARATO, F. K. Ensaio sobre o juizo de constitucionalidade de políticas públicas. São Paulo: Malheriros, v. 2, 1997.

DAMODARAN, A. Gestão estratégica do risco: uma referência para a tomada de riscos empresariais. Porto Alegre-RS: Bookman, 2009.

DANTAS, B. O risco de infantilizar a gestão pública por Bruno Dantas, 2018. Disponível em: < https://jornalggn. com.br/gestao-publica/o-risco-de-infantilizar-a-gestao-publica-por-bruno-dantas/>. Acesso em 23 jan. 2022.

DE CARVALHO, L. B. Governo digital e direito administrativo: entre a burocracia, a confiança e a inovação. Revista de Direito Administrativo, São Paulo-SP, 279, 2020. 115-148.

DE OLIVEIRA, R. A.; AZEREDO, A. D. O pináculo da virtude: o mito da ineficiência pública e a virtude do setor privado. Revista Sítio Novo, 5, n. 2, 2020. 36-44. Disponível em: < https://sitionovo.ifto.edu.br/index.php/sitionovo/article/view/894>. Acesso em: 9 jul. 2021.

DEZAN, S.; LOPES, A. Elementos para uma teoria da fundamentação da decisão administrativa: uma abordagem à luz da hermenêutica. Revista de Direito Administrativo \& Constitucional, v. 21, n. 83, 2021.

DWORKING, R. The model of rules. Univeristy of Chicago Law Review, p. 14-46, 1967.

DWORKIN, R. Do liberty and equality conflict?. In: BARKER, P. Living as Equals, 1996. p. 39-58.

FERRAZ, S. O controle da administração pública na Constituição de 1988. Revista de Direito Administrativo, 1992. 64-73.

FRANÇA, V. D. R. Eficiência administrativa na Constituição Federal. Revista de Direito Administrativo, 2000. 165-177.

FRANCESCO, M. Principio di Legalità e Semplificażione Dell'attività amministrativa - Profili Critici e Principi Ricostruttivi. Nápoles: Maggio, 2000.

FREITAS, J. As políticas públicas e o direito fundamental à boa administração. Revista do Programa de Pós-Graduação em Direito - UFC, 2015. 195-217.

G1. Japão reconstrói rodovia destruída por terremoto em apenas seis dias. G1, 2011. Disponível em: <http://g1.globo.com/tsunami-no-pacifico/noticia/2011/03/japao-reconstroi-rodovia-destruida-por-terremoto-em-apenas-seis-dias.html>. Acesso em: 02 jul 2021.

G1. Viaduto do Eixão que desabou há 15 meses será liberado nessa terça, diz GDF. G1, 2019. Disponível em: <https:/g1.globo.com/df/distrito-federal/noticia/2019/06/03/viaduto-de-eixao-que-desabou-ha-15-meses-sera-liberado-nesta-terca-diz-gdf.ghtml>. Acesso em: 2 jul 2021.

GROISMAN, E. Crisis y Actualidad del Derecho Administrativo Económico. Revista de Derecho Industrial, 1993. 894.

GUIMARÃES, F. V. O Direito Administrativo do Medo: a crise da ineficiência pelo controle. 2016. Disponível em $<$ http://www.direitodoestado.com.br/colunistas/fernandovernalha-guimaraes/o-direito-administrativo-do-medo-a-crise-da-ineficiencia-pelo-controle> . Acesso em: 23 jan 2022. 
INSTITUTO BRASILEIRO DE GOVERNANÇA CORPORATIVA. Gerenciamento de riscos corporativos: evolução em governança e estratégia. São Paulo-SP: IBGC, 2017.

LIMA, L. V. D. A.; RUFINO, M. A.; MACHADO, M. R. Criando dificuldades para vender facilidades: corrupção, burocracia e crescimento corporativo no Mercosul. Revista de Contabilidade e Organizações, 13, 2019. 64-74. Disponível em: < https://www.revistas.usp.br/rco/article/view/158324/157722>. Acesso em: 09 jul. 2021.

LOPES, K.; MACADAR, M. A.; LUCIANO, E. M. Valor Público: o Cidadão no Centro da Gestão Pública. In: BARBOSA, A. F. Pesquisa Sobre o Uso das Tecnologias de Informação e Comunicação no Setor Público Brasileiro. [S.1.]: [s.n.], 2018. p. 75-84.

LOUREIRO, M. R. G. Série Pensando o Direito - No 33/2019, Brasília, 2009. Disponível em: <http:// pensando.mj.gov.br/wp-content/uploads/2015/07/33Pensando_Direito1.pdf>.

LUNELLI, R. G. M. O princípio da eficiência no art. 37 da Constituição Federal: a burocratização da desburocratização, 2014. Disponível em: <https://jus.com.br/artigos/28675/o-principio-da-eficiencia-no-art-37-da-constituicao-federal-a-burocratizacao-da-desburocratizacao $>$. Acesso em: 02 de fevereiro de 2020.

MACIEL, C. S. F. dos S.; AVELAR, M. M. Atos lesivos à Administração Pública e o princípio do bis in idem: uma análise do sistema legal de defesa da integridade administrativa. In: FORTINI, Cristiana (Coord). Corrupção e seus múltiplos enfoques jurídicos. Belo Horizonte: Fórum, 2018.

MEIRELLES, H. L. Direito Administrativo Brasileiro - 29ed. São Paulo: Malheiros, 2004.

MELLO, C. A. B. D. Curso de Direito Administrativo. São Paulo: Malheiros, 2013.

MENDES, G. F.; BRANCO, P. G. Curso de Direito Constitucional. 8ª Ed. São Paulo: Saraiva, 2013.

MIRANDA, R. F. D. A. Implementando a gestão de riscos no setor público. Belo Horizonte: Fórum, 2019.

MODESTO, P. O controle jurídico do comportamento ético da Administração Pública no Brasil. Revista Eletrônica sobre a Reforma do Estado, 2007.

MONTEZANO, L.; DA COSTA JÚNIOR, R. L.; RAMOS, K. H. C; MELCHIADES, A. T. Percepção de Servidores Públicos Quanto à Implementação da Gestão de Riscos em uma Secretaria do Governo Federal do Brasil. Economia \& Gestão, 2019. p. 77-94.

MORAES, A. D. Direito Constitucional. São Paulo: Atlas, 2004.

MOREIRA, F. R.; DA SILVA FILHO, D. A.; NZE, G. D. A.; DE SOUSA JÚNIOR, R. T.; NUNES, R. R. Evaluating the Performance of NIST's Framework Cibersecurity Controls Throught a Constructivist Multicriteria Methodology. IEEE Access. v. 9. p. 129605-129618, 2021.

NEVES, Marcelo. A constitucionalização simbólica. São Paulo: WMF Martins Fontes, 2018.

OLECHOWSKI, A.; OEHMEN, J.; SEERING, W.; BEN-DAYA, M. The professionalization of risk management: What role can the ISO 31000 risk management principles play. International Journal of Project Management, v. 34, p. 1568-1578, 2016.

OLIVEIRA, G. J. D. A insegurança jurídica das empresas e os acordos de leniência na legislação anticorrupção brasileira. Migalhas, 2017. Disponível em: < https://www.migalhas.com.br/depeso/259553/a-inseguranca-juridica-das-empresas-e-os-acordos-de-leniencia-na-legislacao-anticorrupcao-brasileira $>$. Acesso em: 20 de março de 2020.

OLIVEIRA, K. P. D.; PAULA, A. P. P. D. Hebert Simon e os limites do critério de eficiência na administração pública. Cadernos de Gestão Pública e Cidadania, 2014. 113-126. 
OLLAIK, L. G. Casoteca de Gestão Pública. TAXIGOV: Inovando no Serviço de Mobilidade de Servidores, 2018. Disponível em: <https://repositorio.enap.gov.br/handle/1/3454>. Acesso em: 30 de março de 2020.

PALMA, J. B. D. Quem é o ‘administrador médio’ do TCU?, 2018. Disponível em: < https://www.jota.info/ paywall? redirect_to=//www.jota.info/opiniao-e-analise/colunas/controle-publico/quem-e-o-administrador-medio-do-tcu-22082018>. Acesso em: 01 de maio de 2020.

PEREIRA, A. C. M. Trinta anos de controle da Administração Pública: À espera de um giro de eficiência. In: HACHEM, D. W.; LEAL, F.; MENDONÇA, J. V. S. D. Transformações do Direito Administrativo: O Estado Administrativo 30 anos depois da Constituição de 1988. Rio de Janeiro: FGV, 2018. p. 27-61.

PEREIRA, L. C. B. Reforma do Estado para a Cidadania. Brasilia: Editora 34, 2011.

POWER, T.; TAYLOR, M. M. Corruption and Democracy in Brazil: The Struggle for Accountability. [S.l.]: University of Notre Dame Press, 2011.

RIBEIRO, L. C. O direito administrativo como caixa de ferramentas e suas estratégias. Revista de Direito Administrativo, v. 272, 2016. 209-249.

SOUZA NETO, C. P. de; SARMENTO, D. Direito constitucional: teoria, história e métodos de trabalho. Belo Horizonte-MG: Fórum, 2012.

TEIXEIRA, V. A. Criando valor público - gestão estratégica no TCU. Página de Liderança, 2012. Disponível em: < http://portal2.tcu.gov.br/ portal/page/portal/TCU/educacao_corporativa/lideranca $>$. Acesso em: 02 jul 2021.

THE INSTITUTE OF INTERNAL AUDITORS. Modelo das três linhas do IIA 2020: uma atualização das três linhas de defesa, Lake Mary, 2020. Disponível em: <https://iiabrasil.org.br/korbilload/upl/editorHTML/uploadDireto/20200758glob-th-editorHTML-00000013-20072020131817.pdf>. Acesso em: 02 jul 2021.

TRANSPARÊNCIA INTERNACIONAL. Índice de Percepção da Corrupção 2019. Transparência Internacional, 2019. Disponível em: <https://transparenciainternacional.org.br/ipc/>. 
Para publicar na revista Brasileira de Políticas Públicas, acesse o endereço eletrônico www.rbpp.uniceub.br

Observe as normas de publicação, para facilitar e agilizar o trabalho de edição. 